\title{
Comparative Study of Small Office Layout based on Amount of Communication and Knowledge Creation Behavior
}

\author{
Azizah Md Ajis ${ }^{1, a^{*}}$, Shin Muramatsu ${ }^{2, b}$ and Ryusuke Naka ${ }^{1, c}$ \\ ${ }^{1}$ Kyoto Institute of Technology, Japan \\ ${ }^{2}$ Research Institute of Human and Nature, Japan \\ a*azizahmdajis@gmail.com, ${ }^{b}$ muramatsushin0517@gmail.com, ㄷnaka@kit.ac.jp
}

Keywords: Amount of Communication, SECI Model, Office Layout, Workplace Design

\begin{abstract}
The increasing use of electronically mediated communication among workers when dealing with collocated group members has become unavoidable. Besides, communication is a vital part of sustainability strategy of an organization in order to keep abreast with business agility, as well as increasing organization's intellectual productivity. However, the importance of physical workplace as a place supporting face to face communication cannot be denied since it is one of the factors of successful accomplishment of complex group tasks and activities. In this paper, we explored and compared the characteristics of two small office layout and physical settings on group's communication while performing their work process - in this case we adopted SECI Model behaviors. The ethnographic and cross-sectional studies were conducted, and relationship between physical design, communication and work process have been explored by considering the office layout of two project groups at research institution in Japan. The findings highlighted the differences in distribution of amount of communication in these two layouts based on several measurements such as communication contents, unit boundaries, SECI behaviors and so on. Based on the result of the study, we suggest the layout and physical settings that foster communicative workplace as well as supporting their work process.
\end{abstract}

\section{Introduction and Background of Study}

In recent years, the concept of knowledge creation and intellectual productivity of knowledge worker has become a popularly discussed topic since the world economy has shifted from 'monozukuri-based' towards the era of 'knowledge-based'. With knowledge and information have become the central resources of creativity and innovation, the organization need to be more proactive in creativity, innovativeness and knowledge-based in order to keep abreast with business agility and competitiveness. Thus, the intellectual productivity of its worker as well has become a concern.

This has driven researchers to explore the relationship between human within organization including their living environment and conditions [1], [2]. The results of these studies showed that many scholars have describe and developed various types of models based on two-components behavior and physical workplace with a specific measure on work style [3], collaboration [4], knowledge sharing [5], task characteristics [6], organizational learning [7] and creative social [8]. Behavior in this case refers to activities that related to work. However, shaping office layout for such behaviors must considered the link between them - communication among workers [7], [9]-[12].

Communication in the workplace has often been associated with how worker carries information, messages, clues, ideas, emotion and knowledge as such with organizational performance, business growth and effectiveness. This means that communication in the workplace is a snapshot showing how an organization works, how it affect the process of work being done and how to make it understood by each other. And the mutual exchange of ideas, viewpoints and beliefs that conversation entail thus allows for knowledge creation across organization [13], [14]. However, the increasing use of electronically mediated communication among worker when dealing with a collocated group 
members has become a phenomenon. Despite the rapid innovation in office ICT, research continues to underline the importance of workplace communication and the design of physical workplace as they are the factors of successful accomplishment of complex group tasks as well as enhancing intellectual productivity of workers [15].

The purpose of this study is to explore the relationship between the workplace design and its effect on project group verbal communication by comparing two small office layout. The measurement parameter was looked at amount of communication (henceforth stated as AOC) and knowledge creation behavior that covers several behaviors that has not yet being encompassed in previous studies by adopting 12 SECI behaviors of knowledge creation process. 12 SECI behaviors are an extended studies from SECI Model [14] and used by NOPA (New Office Promotion Association, Japan) for their creative office study [16].

\section{Methods}

Office Layout: 2 small office of project-based research groups at research institution located in Japan have been chosen due to its nature of work that falls under knowledge-based organization category as the institution relies on human capital and the use of knowledge as primary production factor. Each research group had their own office spaces approximately $180 \mathrm{~m}^{2}$. Each research group designed their own office layout according to their preference, equipped with computers, furniture, telephone and standard office materials and equipment.

Data Collection and Measurement: Ethnography method was adopted due to its suitability and applicable method for the nature of this research. To obtain information regarding activities performed - communication pattern - space occupancy by researchers, semi structured interview was conducted to project leaders and researchers. Each session took about 45 to 90 minutes per person. Observation was conducted using overt observational research where the subjects were informed and the purpose of observation was explained. Although the behavior of participants may alter due to the presence of the researcher, the advantage of this technique is that the data can be openly recorded. Observation was conducted with 3 observers monitoring 5 participants for 5 days in each group during office hour starting from 930 in the morning until 1700 in the evening. A total of 75 hours was spent to collect the data with 440 communications occurrence were collected. The measurement recorded for this research purposes including - 1) AOC (duration and frequency of communication occurrence), 2) communication contents, 3) communication trigger, 4) unit boundaries, 5) social network, 6) posture, 7) tool used, 8) space occupancy, and 9) SECI behavior.

Procedure: The procedures during observation -1) all participants were given a briefing about the purpose of study and type of information that would be collected during observation, 2) all observers standing at one objective point to ensure the participants and the situation at field settings can be seen and grasp relatively, 3) participants were given a survey sheet after one communication event ends and needs to fulfill information related to the communication performed, and 4) in order to grasp people movement, presence rate of people in the office as well as density, video recording and snapshot were taken during observation.

Data Analysis: To achieve the objectives of this research, data analysis was conducted in three different method. First, data from interview transcribed and analyzed using content analysis. The contents consisting knowledge creation activities were classified into SECI four modes dimension socialization, externalization, combination and internalization. To analyze the behavior of researchers, knowledge creation activities were codified accordingly to 12 SECI behaviors code. Second, IBM SPSS Statistics 22 was used for all analysis from observation. Evaluation on the overall AOC according to SECI behaviors and space occupancy was carried out using descriptive statistical method. Whilst, evaluation on the AOC differences according to SECI and non SECI behaviors was carried out using nonparametric ANOVA the Kruskal-Wallis Test since the data is non-normally distributed. Post hoc analysis using pairwise comparisons test with adjusted $\mathrm{p}$ value using 
Bonferroni's procedure were performed. Third, to see the effect on AOC caused by workplace design, distribution of AOC according to SECI behaviors were plotted on the layout.

\section{Result and Discussion}

Knowledge Creation Behavior: The first objectives of the study is to determine work activities that related to knowledge creation behavior. By understanding the nature of work of researchers, space occupancy during communication can be predicted, thus help in contributing space characteristics needed by this type of work. The result showed in Table 1 presents only part of work activities that has been codified into SECI behavior code. The SECI behavior was classified into four code same as the code used by NOPA in creative office study, but activities in this study were referring to activities on the said organization. Activities performed by both groups almost the same.

Table 1 The 12 SECI behaviors of researchers resulted from content analysis

\begin{tabular}{|c|c|c|c|}
\hline SECI Mode & SECI Code & SECI Behavior Code & Summary of Activities \\
\hline \multirow{3}{*}{$\begin{array}{l}\text { Socialization } \\
\text { tacit - tacit }\end{array}$} & \multirow{3}{*}{ stimulating } & walk around & \multirow{3}{*}{$\begin{array}{l}\text { activities of making contact with related person involved in the research project } \\
\text { to get information, grasping actual condition by visiting the site, experiencing } \\
\text { local people activities, collecting specimen, meeting counterpart researchers, } \\
\text { etc. Most activities carried outside office }\end{array}$} \\
\hline & & to make contact with & \\
\hline & & to feel-see-seen & \\
\hline \multirow{3}{*}{$\begin{array}{l}\text { Externalization } \\
\text { tacit-explicit }\end{array}$} & \multirow{3}{*}{ idea } & light talk & \multirow{3}{*}{$\begin{array}{l}\text { activities of generating ideas from information collected. Having advise / } \\
\text { opinion regarding technical matters, alternative solution of data collection, } \\
\text { brainstorming idea, method or concept, extracting data from sample / specimen } \\
\text { / site measurement and visualize raw data into figure, picture and words. }\end{array}$} \\
\hline & & brainstorm & \\
\hline & & to illustrate / similize & \\
\hline \multirow{3}{*}{$\begin{array}{c}\text { Combination } \\
\text { explicit - explicit }\end{array}$} & \multirow{3}{*}{ finalizing } & $\begin{array}{l}\text { to investigate, analyze, } \\
\text { edit and accumulate }\end{array}$ & \multirow{3}{*}{$\begin{array}{l}\text { activities divided into three types. First, desk job like writing document, } \\
\text { organizing and summarizing data, finalizing accumulated data, establishing } \\
\text { data from experiment, analyzing image and so on. Second, discussion on } \\
\text { making a decision about finalizing data, having Q\&A about theme discussed, } \\
\text { debating with other researchers about the theme as well as about appropriate } \\
\text { methodology and analysis method. Third, presentation of the research output } \\
\text { and getting examined at periodical group meeting, academic conference, } \\
\text { research seminar, special seminar or reserved lecture. }\end{array}$} \\
\hline & & aggresively discuss & \\
\hline & & $\begin{array}{l}\text { getting examined / } \\
\text { listened }\end{array}$ & \\
\hline \multirow{3}{*}{$\begin{array}{l}\text { Internalization } \\
\text { explicit - tacit }\end{array}$} & \multirow{3}{*}{$\begin{array}{c}\text { improve } \\
\text { understanding }\end{array}$} & make a trial & \multirow{3}{*}{$\begin{array}{l}\text { activities that require researchers to improve their skills, knowledge and } \\
\text { understanding as well as spreading the knowledge to others like students and } \\
\text { community. Activities involved such as become a guest speaker at academic } \\
\text { conference, publish a booklet or book, performing a small-scale demonstration } \\
\text { test to transfer potential technology and attending research seminar and } \\
\text { colloquium for further research understanding. }\end{array}$} \\
\hline & & practice / perform & \\
\hline & & self - Improve & \\
\hline
\end{tabular}

Communication Pattern: The second objectives is to look into communication pattern while performing knowledge creation behavior, the AOC was measured by calculating 1) Duration rate the proportion of durations where each researchers verbally communicates on average in each communication event, and 2) Frequency - how frequent each researcher verbally communicated on average. Since the data were not normally distributed for both project group, with a skewness of 8.092 $(\mathrm{SE}=0.178)$ and kurtosis of $72.852(\mathrm{SE}=0.355)$ for Project group 1 (PJ1) and skewness of 5.154( $\mathrm{SE}=0.152)$ and kurtosis scores of 28.453( $\mathrm{SE}=0.303)$ for Project group 2 (PJ2), the result of descriptive analysis of each measurement shown in Table 2. There are four pattern of AOC can be traced from observation (shown in Table 2) and the scores showed a trend to be dominated by pattern PAOC1 in the most variables measured with short duration of communication events for both groups, in this case 1-5 minutes.

The third objectives is to determine whether there is significance differences in AOC when performing SECI behaviors. The scores showed that SECI behaviors have an effect on amount of communication on variables indicated with asterisk. In relation to space characteristics, PJ1 shows that AOC significantly affected by SECI behaviors at circulation area and main aisle, whilst PJ2's AOC significantly affected by SECI behaviors at own workstation and discussion/meeting spaces. SECI behaviors does not affect AOC at the rest of spaces measured in the observation.

Distribution of AOC of SECI Behaviors on Office Layout: The fourth objectives in this research is to examine the space occupancy pattern while performing SECI behaviors. Since SECI 
behaviors have four codes, we choose the most behavior conducted within the office territory. In this case, Combination mode with finalizing behavior code.

Table 2 Results from quantitative analysis

\begin{tabular}{|c|c|c|c|c|c|c|c|}
\hline & & \multicolumn{3}{|c|}{ PJ1 } & \multicolumn{3}{|c|}{ PJ2 } \\
\hline Item & Variables & $f$ & Duration & $H(4)$ & $f$ & Duration & H(4) \\
\hline \multirow{4}{*}{ unit boundaries } & same project group & 113 & $1.0(1.0-3.0)$ & *19.98 & 159 & $2.0(1.0-5.0)$ & ${ }^{*} 15.10$ \\
\hline & different project group & 23 & $3.0(1.0-5.0)$ & $9.21(0.11)$ & 13 & $4.0(2.0-21.0)$ & *23.11 \\
\hline & other division & 40 & $1.5(1.0-3.0)$ & $* 29.11$ & 61 & $2.0(1.0-3.0)$ & *16.60 \\
\hline & external & 14 & $2.0(1.0-3.0)$ & $5.13(0.08)$ & 25 & $3.0(2.0-6.0)$ & $1.02(0.03)$ \\
\hline \multirow{5}{*}{ social network } & project member & 69 & $1.0(1.0-2.0)$ & ${ }^{*} 10.01$ & 119 & $2.0(1.0-8.0)$ & ${ }^{* 10.05}$ \\
\hline & superior & 25 & $2.0(1.0-3.0)$ & *14.45 & 35 & $4.0(1.0-21.0)$ & *35.84 \\
\hline & colleague & 39 & $2.0(1.0-3.0)$ & $* 25.1$ & 62 & $2.0(1.0-4.0)$ & *10.45 \\
\hline & administration staff & 31 & $1.0(1.0-3.0)$ & $8.55(0.11)$ & 39 & $2.0(1.0-7.0)$ & $* 25.04$ \\
\hline & other & 25 & $2.0(1.0-3.0)$ & $4.96(0.08)$ & 23 & $3.0(1.0-10.0)$ & $* 9.82$ \\
\hline \multirow{7}{*}{$\begin{array}{l}\text { comminication } \\
\text { contents }\end{array}$} & knowledge, information & 63 & $2.0(1.0-3.0)$ & ${ }^{*} 23.93$ & 89 & $4.0(2.0-14.0)$ & ${ }^{*} 50.24$ \\
\hline & rule of thumb, know-how & 2 & $4.0(3.0-5.0)$ & $6.05(0.09)$ & 27 & $3.0(1.0-4.0)$ & $*^{*} 14.78$ \\
\hline & idea & 15 & $3.0(1.0-20.0)$ & ${ }^{*} 27.69$ & 6 & $98.5(6.0-180.0)$ & $* 49.76$ \\
\hline & motivation & 1 & $3.0(3.0-3.0)$ & $5.17(0.08)$ & 1 & $0.5(0.5-0.5)$ & $7.23(0.09)$ \\
\hline & resolving problem/ decision making & 74 & $2.0(1.0-3.0)$ & ${ }^{*} 54.98$ & 88 & $2.0(1.0-4.5)$ & ${ }^{*} 43.23$ \\
\hline & chatting & 14 & $2.0(1.0-3.0)$ & *10.03 & 34 & $4.0(1.0-21.0)$ & $* 48.30$ \\
\hline & other & 39 & $1.0(1.0-2.0)$ & *61.97 & 41 & $1.0(1.0-2.0)$ & *80.51 \\
\hline \multirow{8}{*}{ tool used } & notools & 90 & $1.0(1.0-3.0)$ & $3.55(0.07)$ & 102 & $2.0(1.0-4.0)$ & $8.85(0.10)$ \\
\hline & PC & 6 & $2.0(2.0-2.0)$ & $2.89(0.06)$ & 35 & $8.0(3.0-33.0)$ & ${ }^{*} 58.27$ \\
\hline & document & 36 & $1.5(1.0-3.0)$ & $6.01(0.09)$ & 35 & $1.0(1.0-5.0)$ & $4.24(0.07)$ \\
\hline & telephone & 37 & $2.0(1.0-3.0)$ & *15.36 & 68 & $2.0(1.0-3.0)$ & *10.37 \\
\hline & white board & 3 & $6.0(1.0-6.0)$ & *15.94 & 5 & $180.0(17.0-180.0)$ & *94.56 \\
\hline & tv conferenoe & 2 & $103.5(87.0-120.0)$ & $6.07(0.09)$ & 0 & $0.0(0.0-0.0)$ & 0 \\
\hline & memo & 1 & $2.0(2.0-2.0)$ & $1.94(0.05)$ & 5 & $3.0(2.0-5.0)$ & ${ }^{* 13.33}$ \\
\hline & other & 16 & $1.0(1.0-2.0)$ & ${ }^{*} 16.46$ & 16 & $15.0(1.5-33.0)$ & *19.29 \\
\hline \multirow{9}{*}{ space occupancy } & own workstation & 105 & $1.0(1.0-2.0)$ & $0.10(0.03)$ & 131 & $1.0(1.0-3.0)$ & *15.24 \\
\hline & opponent workstation & 32 & $1.0(1.0-2.5)$ & $3.59(0.07)$ & 33 & $2.0(1.0-8.0)$ & $4.43(0.07)$ \\
\hline & circulation area & 27 & $1.0(1.0-3.0)$ & ${ }^{* 10.16}$ & 38 & $2.0(1.0-4.0)$ & $1.49(0.04)$ \\
\hline & main aisle & 4 & $1.0(1.0-3.0)$ & *11.80 & 0 & $0.0(0.0-0.0)$ & 0 \\
\hline & photocopier area & 2 & $3.0(1.0-3.0)$ & $7.29(0.10)$ & 1 & $4.0(4.0-4.0)$ & $2.64(0.05)$ \\
\hline & discussion/ meeting space & 5 & $3.0(3.0-8.0)$ & $0.95(0.04)$ & 33 & $21.0(1.0-33.0)$ & *33.41 \\
\hline & storage / cabinet area & 3 & $1.0(1.0-4.0)$ & $1.05(0.04)$ & 0 & $0.0(0.0-0.0)$ & 0 \\
\hline & refreshment area & 0 & $0.0(0.0-0.0)$ & 0.00 & 1 & $3.0(3.0-3.0)$ & $7.23(0.09)$ \\
\hline & other & 10 & $15.5(5.0-24.0)$ & $7.12(0.10)$ & 22 & $4.5(2.0-7.0)$ & $6.02(0.08)$ \\
\hline
\end{tabular}

* $f=$ frequency of commin

Pattern of Amount of Communication

(PAOC1) when frequency increased, its duration decreased
(PAOC2) when frequency increased, its duration also increased
(PAOC3) when frequency decreased, its duration increased
(PAOC4) when frequency decreased, its duration also decreased

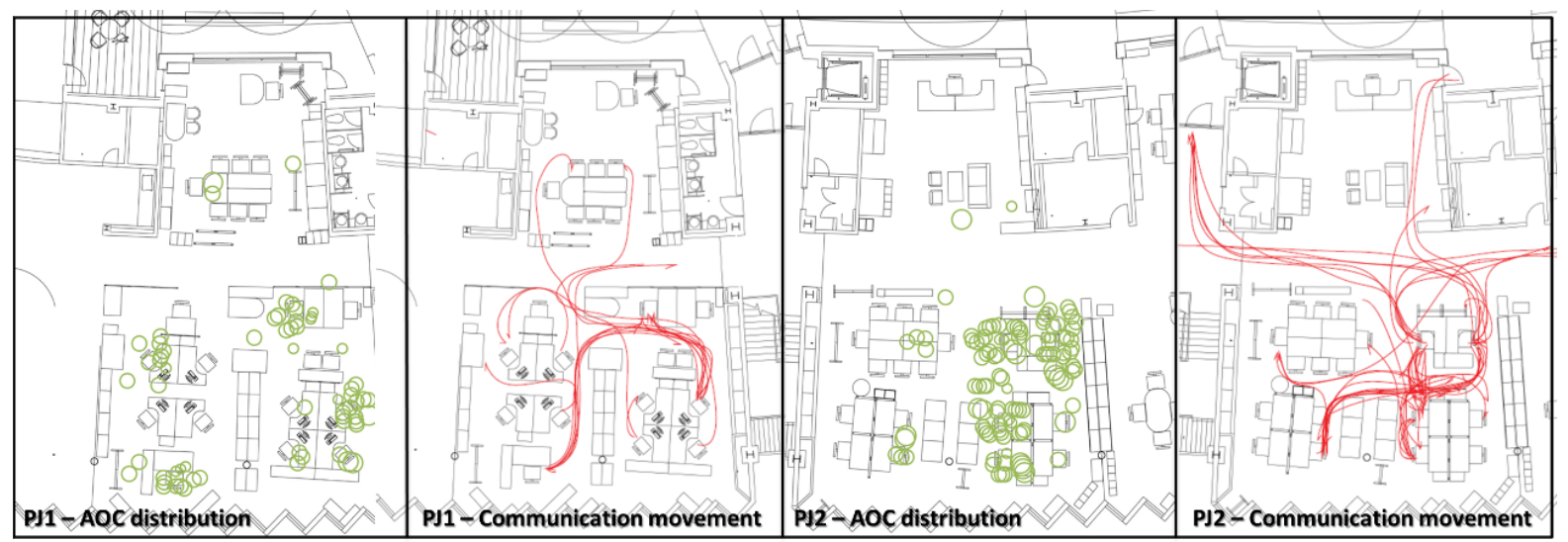

Fig 1. Comparison of SECI - Combination Behavior on PJ1 and PJ2.

The distribution of AOC on the office layout were influence by several factors that that may clarify the office physical design characteristics for this type of work activities-1) Visibility factor- type of workstation allocated in PJ1 and PJ2 were both different. PJ1 has an island type workstation with low partition and this characteristics allows researchers see each other face from their own workspace. Whilst, PJ2 has a typical cubicle workstation with high partition. Although this kind of workstation provide high privacy and concentration, when look at the movement pattern of researchers when conducting I-Finalizing Behavior, it shows more movement for communication compared to PJ1. 2) Proximity factor - High AOC was traced with more than 30 minutes with frequent occurrence on S-Stimulating Behavior when discussion/meeting space allocated adjacent to workstation area in PJ2 compared to PJ1, which allocated far from workstation area. The number of people involved in this 
behavior always more than 2 persons. 3) Circulation factor - support spaces including filing, storage, pantry, print and copy area were allocated under this category. Non-SECI communication by accident / ad hoc frequently occurred at this area with low level of AOC.

\section{Conclusion}

This study has presented how the office physical design may influence the amount of communication among worker when performing knowledge creation activities. The findings in this study reveals that these two factors can be considered when planning a spatial setting. However, the SECI behavior and amount of communication may differ to different organization due to its nature of work practiced by profession and also the culture of organization. Since, this study only conducted at small scale of office spatial settings, the results may indicate on certain spatial characteristics. Therefore, there is a need to expand the study by exploring bigger organization, so that other spatial characteristics can be discovered thus, strengthen the study on this factor.

\section{References}

[1] S. Murakami, "Chitekiseisansei Kenkyu no Susume," in Kenchiku to ChitekiSeisansei, 2010, pp. $8-15$.

[2] H. Takai, "Three-tier Model of Intellectual Productivity," in Kenchiku to Chitekiseisansei - Chiei o Souzosuru Kenchiku, 2010, pp. 16-23.

[3] A. Mori, K. Tsunekawa, A. Kato, and P. C. Le Roux, "A study on relationships among plan compositions, work-styles and communication behaviors in office," J. Archit. Planning, Environ. Eng. AIJ, vol. 551, pp. 129-134, 2002.

[4] J. B. Stryker, M. D. Santoro, G. F. Farris, and S. Member, "Creating Collaboration Opportunity: Designing the Physical Workplace to Promote High-Tech Team Communication," IEEE Trans. Eng. Manag., vol. 59, no. 4, pp. 609-620, 2012.

[5] R. Appel-Meulenbroek, "Knowledge sharing through co-presence: added value of facilities," Facilities, vol. 28, no. 3/4, pp. 189-205, 2010.

[6] M. J. Hatch, "Physical barriers, task characteristics and interaction activity in research and development firm," Adm. Sci. Q., vol. 32, pp. 387-399, 1987.

[7] V. W. Kupritz and T. Hillsman, "The Impact of the Physical Environment on Supervisory Communication Skills Transfer,” J. Bus. Commun., vol. 48, no. 2, pp. 148-185, Mar. 2011.

[8] K. Sailer, "Creativity as social and spatial process," Facilities, vol. 29, no. 1/2, pp. 6-18, 2011.

[9] C. Greene and J. Myerson, "Space for thought: designing for knowledge workers," Facilities, vol. 29, no. 1/2, pp. 19-30, 2011.

[10] B. P. Haynes, "The impact of the behavioural environment on office productivity," J. Facil. Manag., vol. 5, no. 3, pp. 158-171, 2007.

[11] D. Kobayashi and Y. Yanagisawa, "Office ni Okeru Communication Kuukan no Kousei to Tsukawarekata/ Hyouka ni kansuru Kenkyu," Archit. Inst. Japan, vol. 5224, no. Hokuriku, pp. 447-448, 2002.

[12] Y. Midorikawa, T. Ikaga, H. Sato, and T. Warita, "Office no Kenchiku Kuukan to Communication ga Chitekiseisansei ni Ataeru Eikyou," Archit. Inst. Japan, vol. 4038, no. Kanto, pp. 149-152, 2010.

[13] G. Von Krogh, K. Ichijo, and I. Nonaka, Enabling Knowledge Creation - How to Unlock the Mystery of Tcit Knowledge and Release the Power of Innovation. 2000, pp. 1-292.

[14] I. Nonaka and H. Takeuchi, The Knowledge Creating Company. 1995, pp. 1-295.

[15] J. B. Stryker and M. D. Santoro, "Facilitating Face-to-Face Communication in High-Tech Teams," Res. Manag., vol. 55, no. 1, pp. 51-56, Jan. 2012.

[16] NOPA, “Creative Office Report V. 2.0,” New Off. Promot. Assoc., vol. 2, pp. 1-47, 2008. 